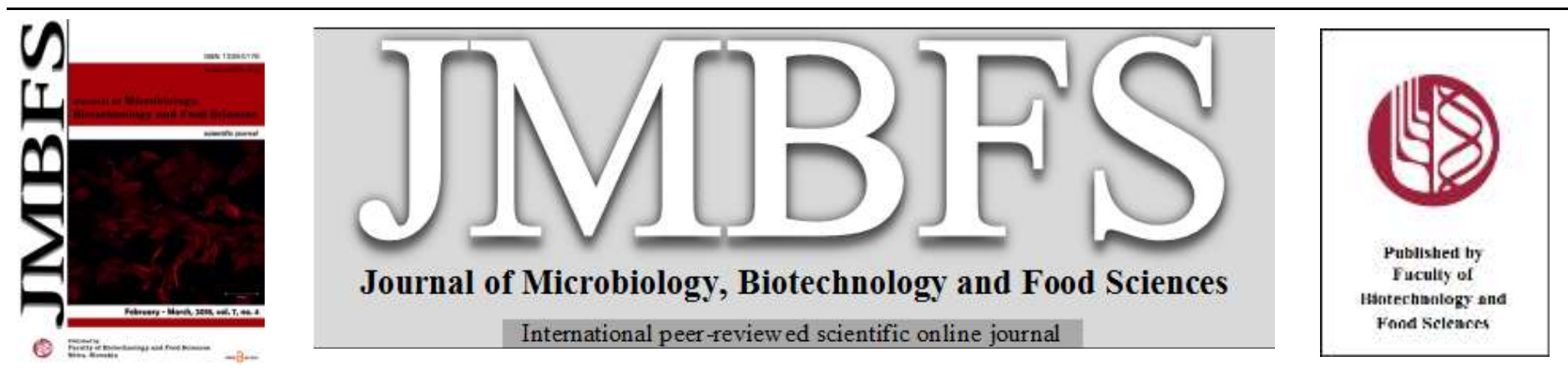

\title{
DETERMINATION OF NUTRITIONAL PARAMETERS OF COMMERCIAL AND HOMEMADE JAMS
}

\section{Andrea Kántor*, Loránd Alexa, Béla Kovács, Nikolett Czipa}

\author{
Address(es): Andrea Kántor, \\ *Institute of Food Science, Faculty of Agricultural and Food Sciences and Environmental Management, University of Debrecen, H-4032 Böszörményi street 138, \\ Debrecen, Hungary. Tel: +36 308351422 .
}

*Corresponding author: kantor.andrea@agr.unideb.hu

doi: 10.15414/jmbfs.2017.7.4.407-411

\section{ARTICLE INFO}

Received 16. 10. 2017

Revised 29.11.2017

Accepted 13. 12. 2017

Published 1. 2. 2018

\section{Regular article}

orten Acctss

\begin{abstract}
In this present study, 26 fruit jams with different botanical origin were examined. 10 samples were commercial and 16 samples were homemade products. Dry matter and water contents, total phenolic contents, flavonoid contents and total acid contents of jams were measured. Important differences were determined in these parameters. Commercial products had higher dry matter contents than the homemade samples. The highest total phenolic content was measured in homemade blackberry jam. One of the homemade plum jams and homemade blackberry jam showed the highest flavonoid contents. Higher than $20 \%$ of total acid content was determined in one of the homemade plum jams. According to the LSD test more significant differences were determined among the analysed jam samples in total phenolic content and flavonoid content. In case of total acid concentration there were not determined any significant differences.
\end{abstract}

Keywords: jams, TP contents, flavonoid contents, total acid contents

\section{INTRODUCTION}

Several studies have been written about the positive effects of the consumption of fruits and vegetables on human health (Du Toit et al., 2001). Plant foods contain extremely healthy compounds such as phenolic compounds, essential fatty acids, vitamins, minerals, tannins, carotenoids, fibre, etc. (Nowak et al., 2014). Phenolic compounds are secondary plant metabolites which are necessary for the plant's growth and development, and the protection against adverse factors, like drought, UV radiation, infections, etc. (Ryu et al., 2016; Tiwari, Sangwan \& Sangwan, 2016). These compounds could also have beneficial effects on human consumers, for instance, phenolic compounds also play an important role in the determination of foods' quality, nutritional value, and organoleptic characteristics. Furthermore, they are the major bioactive components which could be beneficial for human health (Nowak et al., 2014). These benefits are various, and are in close relation with their antioxidant capacities, this is why antitumor, antiulcer and antiinflammatory effects could be attributed to these fruits (Olech et al., 2012).

Phenolic compounds contain different chemical material, for example flavonoids, which demonstrate high capacity for capturing free radicals, this is why they have an important role in the fight against oxidative stress and the prevention of cancer, cardiovascular diseases, etc. (Morelli and Prado, 2012).

According to the statistical data of the $2015^{\text {th }}$ year, the annual fruit consumption was $45.8 \mathrm{~kg} /$ capita. As for different kinds of fruit, the average consumption of fruits was the following: citrus fruits: $7.2 \mathrm{~kg}$, peach: $3 \mathrm{~kg}$, apricot: $0.8 \mathrm{~kg}$, cherry: $1.2 \mathrm{~kg}$, plum: $1.3 \mathrm{~kg}$, strawberry, raspberry and currant: $0.9 \mathrm{~kg}$, fruit preparations: $0.6 \mathrm{~kg} /$ capita $(\mathrm{KSH})$.

Various products could be prepared by using fruits as raw materials. In Hungary the most popular fruit products are pálinka, jams, preserves, juices and dried fruits. Jams are often used as the stuffing of bakery products, or could be consumed with pastas, but it is also common to eat it with bread or by itself.

- ,'Jam' is a mixture, brought to a suitable gelled consistency, of sugars, the pulp and/or purée of one or more kinds of fruit and water."

-,,'Extra jam' is a mixture, brought to a suitable gelled consistency, of sugars, the unconcentrated pulp of one or more kinds of fruit and water. However, rosehip extra jam and seedless raspberry, blackberry, blackcurrant, blueberry and redcurrant extra jam may be obtained entirely or in part from unconcentrated purée of the respective fruits. Citrus extra jam may be obtained from the whole fruit, cut into strips and/or sliced. The following fruits may not be used mixed with others in the manufacture of extra jam: apples, pears, clingstone plums, melons, water-melons, grapes, pumpkins, cucumbers and tomatoes."
,,- 'Jelly' is an appropriately gelled mixture of sugars and the juice and/or aqueous extracts of one or more kinds of fruit."

- „'Marmalade' is a mixture, brought to a suitable gelled consistency, of water, sugars and one or more of the following products obtained from citrus fruit: pulp, purée, juice, aqueous extracts and peel."

- "The name 'jelly marmalade' may be used where the product contains no insoluble matter except possibly for small quantities of finely sliced peel." (Official Journal of the European Communities, 2002).

Jams with decreased energy content and diabetic jams could be categorized as special jams, which contain sweeteners instead of sugar in general (Kanyó et al., 2015).

The aim of our research was to determine the nutritional parameters of jams produced by using different fruits, and to compare these values in homemade and on market products.

\section{MATERIAL AND METHODS}

\section{Samples}

In this study, 26 samples have been analysed, which contained 16 homemade jam samples and 10 samples bought from the markets. The origin of the samples is Hungarian, except peach, (B10), orange (B9 and H9) and lemon (H1) jams. For the production of homemade jams, the fruits were grown in Hajdú-Bihar County. The analysed samples are shown in Table 1.

\section{Determination of water and dry matter content}

Petri dishes were dried in oven on $103 \pm 1^{\circ} \mathrm{C}$ for $30 \mathrm{~min}$, then cooled down in desiccator and their weight were measured

The analysed samples were homogenized before the analysis, then 2 grams of them were measured into the dishes. Then the dishes containing the samples had been put into the oven on $65 \pm 1^{\circ} \mathrm{C}$ and dried to constant weight, then cooled in desiccator. After cooling, the common weight of the dish and the sample, then water content had been calculated by using the original and the dried weight of the dishes and the samples. The results were presented in percentage. The difference of $100 \%$ and water content gives dry matter content in percentage. 
Table 1 Properties of examined samples

\begin{tabular}{|c|c|c|c|}
\hline & Commercial & Place of origin & Fruit content (\%) \\
\hline B1 & Rosehip (Rosa canina) & n.d. & 50 \\
\hline B2 & Blackberry (Rubus caesius) & Hungary & 60 \\
\hline B3 & Blueberry (Vaccinium myrtillus) & Hungary & 50 \\
\hline B4 & Plum (Prunus domestica) & Hungary & 350 \\
\hline B5 & Apricot (Prunus armeniaca) & Hungary & 60 \\
\hline B6 & Cherry (Cerasus vulgaris) & Hungary & 60 \\
\hline B7 & Strawberry (Fragaria ananasa) & Hungary & 60 \\
\hline B8 & Raspberry (Rubus ideaus) & Hungary & 60 \\
\hline B9 & Orange (Citrus sinensis) & n.d. & 28 \\
\hline \multirow[t]{2}{*}{ B10 } & Peach (Persica vulgaris) & Greece & 55 \\
\hline & Homemade & & \\
\hline H1 & Lemon (Citrus limon) & n.d. & n.d. \\
\hline $\mathbf{H 3}$ & Blackberry (Rubus caesius) & Hajdú-Bihar & n.d. \\
\hline H4 & Plum (Prunus domestica) & Hajdú-Bihar & n.d. \\
\hline H5 & Apricot (Prunus armeniaca) & Hajdú-Bihar & n.d. \\
\hline H6 & Cherry (Cerasus vulgaris) & Hajdú-Bihar & n.d. \\
\hline H7 & Strawberry (Fragaria ananasa) & Hajdú-Bihar & n.d. \\
\hline H8 & Raspberry (Rubus ideaus) & Hajdú-Bihar & n.d. \\
\hline H9 & Orange (Citrus sinensis) & n.d. & n.d. \\
\hline H10 & Peach (Persica vulgaris) & Hajdú-Bihar & n.d. \\
\hline H11 & Plum (Prunus domestica) & Hajdú-Bihar & n.d. \\
\hline H12 & Plum (Prunus domestica) & Hajdú-Bihar & n.d. \\
\hline H13 & Plum (Prunus domestica) & Hajdú-Bihar & n.d. \\
\hline H14 & Plum (Prunus domestica) & Hajdú-Bihar & n.d. \\
\hline H15 & Bullace (Prunus domestica subsp. Syriaca) & Hajdú-Bihar & n.d. \\
\hline H16 & Cherry (Cerasus vulgaris) & Hajdú-Bihar & n.d. \\
\hline H17 & Strawberry (Fragaria ananasa) & Hajdú-Bihar & n.d. \\
\hline
\end{tabular}

\section{Determination of acid content}

Before the analysis the samples were homogenized and 20 grams were measured into Erlenmeyer flasks $(250 \mathrm{ml}) .150 \mathrm{ml}$ distilled water was added to each sample. The mixtures were placed into water bath $\left(85-95^{\circ} \mathrm{C}\right.$ for $\left.30 \mathrm{~min}\right)$. After heating the samples were filtered and volume up to $250 \mathrm{ml}$ with distilled water. $25 \mathrm{ml}$ samples were taken out from mixtures into volumetric flasks $(100 \mathrm{ml})$. It was volume up to $100 \mathrm{ml}$ with distilled water. The diluted samples were poured into Erlenmeyer flasks $(200 \mathrm{ml})$ and they were titrated with potassium hydroxide solution $(0,1 \mathrm{M})$ by using fenoftalein indicator, until pink colour appeared. Total acid content was calculated by an equation and the result was expressed in citric acid.

\section{Determination of total phenolic and flavonoid}

Total phenolic content was determined according to Folin-Ciocalteu method (Singleton et al., 1999). Flavonoid content was measured method of Kim et al. (2003).

\section{Statistical analysis}

All analytical analysis was carried out in triplicate. Data are described using general terms (mean, standard deviation) and One-Way ANOVA (LSD test). SPSS for windows (version 13) was used to the calculations.

\section{RESULTS AND DISCUSSION}

Dry matter contents are shown in Table 2. Based on these results, commercial jams showed higher dry matter contents than homemade jams, except for H4, H6 and H16 samples. Dry matter contents of commercials jams (B1-B10) ranged from $40 \%$ to $70 \%$ however in the homemade samples $(\mathrm{H} 1-\mathrm{H} 17)$ these results were in wide range (20-70\%). Dry matter content was between 40 and $50 \%$ in 10 samples. Outlier values were determined in commercial peach (B10). Examining the jams with same fruit origin, commercial blackberry (B2) showed two times higher dry matter content, then the homemade jams. In case of plum jams generally the commercial plum jams showed higher dry matter content except for $\mathrm{H} 4$ sample. Important differences were determined in case of commercial and homemade apricot, orange and peach jams. Very similar dry matter contents were measured in case of commercial and homemade cherry and raspberry jams. The commercial strawberry jam showed higher dry matter content, than homemade strawberry jams, however this difference was not important.

Table 2 Nutritional parameters of examined samples

\begin{tabular}{cccccccccc}
\hline & & & & \multicolumn{2}{c}{ TPC (mgGAE/100g) } & \multicolumn{3}{c}{$\begin{array}{c}\text { Flavonoids } \\
\text { (mgCE/100g) }\end{array}$} & \multicolumn{2}{c}{ Acid content (\%) } \\
\hline $\begin{array}{c}\text { Sample } \\
\text { number }\end{array}$ & Type & $\begin{array}{c}\text { Dry matter } \\
\text { content }(\%)\end{array}$ & $\begin{array}{c}\text { Moisture } \\
\text { content }(\%)\end{array}$ & Wet & Dry & Wet & Dry & Wet & Dry \\
\hline B1 & Rosehip (Rosa canina) & $66.1 \pm 0.8$ & $33.9 \pm 0.8$ & $283 \pm 14$ & $428 \pm 22$ & $125 \pm 7$ & $189 \pm 11$ & $3.32 \pm 0.07$ & $5.01 \pm 0.11$ \\
\hline B2 & Blackberry (Rubus caesius) & $42.2 \pm 0.2$ & $57.8 \pm 0.2$ & $234 \pm 12$ & $556 \pm 27$ & $61.6 \pm 0.8$ & $146 \pm 2$ & $3.24 \pm 0.06$ & $7.68 \pm 0.15$ \\
\hline B3 & $\begin{array}{c}\text { Blueberry (Vaccinium } \\
\text { myrtillus) }\end{array}$ & $68.2 \pm 1.1$ & $31.8 \pm 1.1$ & $127 \pm 1$ & $187 \pm 1$ & $44.7 \pm 3.5$ & $65.6 \pm 5.1$ & $1.90 \pm 0.08$ & $2.79 \pm 0.12$ \\
\hline B4 & Plum (Prunus domestica) & $57.9 \pm 1.8$ & $42.1 \pm 1.8$ & $343 \pm 9$ & $592 \pm 15$ & $186 \pm 12$ & $321 \pm 21$ & $4.67 \pm 0.24$ & $8.06 \pm 0.42$ \\
\hline B5 & Apricot (Prunus armeniaca) & $41.0 \pm 0.0$ & $59.0 \pm 0.0$ & $179 \pm 12$ & $436 \pm 28$ & $97.2 \pm 4.9$ & $237 \pm 12$ & $4.23 \pm 0.09$ & $10.3 \pm 0.2$ \\
\hline B6 & Cherry (Cerasus vulgaris) & $42.3 \pm 0.0$ & $57.7 . \pm 0.0$ & $147 \pm 10$ & $348 \pm 24$ & $58.5 \pm 1.8$ & $138 \pm 4$ & $4.01 \pm 0.02$ & $9.48 \pm 0.05$ \\
\hline B7 & Strawberry (Fragaria ananasa) & $44.7 \pm 0.2$ & $55.3 \pm 0.2$ & $172 \pm 10$ & $384 \pm 22$ & $39.0 \pm 0.6$ & $87.2 \pm 1.4$ & $2.98 \pm 0.02$ & $6.66 \pm 0.03$ \\
\hline B8 & Raspberry (Rubus ideaus) & $41.4 \pm 0.4$ & $58.6 \pm 0.4$ & $141 \pm 8$ & $340 \pm 20$ & $31.4 \pm 1.6$ & $75.8 \pm 3.9$ & $5.03 \pm 0.59$ & $12.2 \pm 1.4$ \\
\hline B9 & Orange (Citrus sinensis) & $66.7 \pm 0.7$ & $33.3 \pm 0.7$ & $85.9 \pm 4.9$ & $129 \pm 7$ & $11.8 \pm 0.5$ & $17.7 \pm 0.8$ & $1.81 \pm 0.12$ & $2.71 \pm 0.18$ \\
\hline & & & & & & & & &
\end{tabular}




\begin{tabular}{|c|c|c|c|c|c|c|c|c|c|}
\hline B10 & Peach (Persica vulgaris) & $81.4 \pm 0.8$ & $18.6 \pm 0.8$ & $50.1 \pm 8.7$ & $61.5 \pm 10.7$ & $17.0 \pm 0.2$ & $20.8 \pm 0.2$ & $1.98 \pm 0.03$ & $2.43 \pm 0.04$ \\
\hline H1 & Lemon (Citrus limon) & $63.1 \pm 0.3$ & $36.9 \pm 0.3$ & $59.8 \pm 0.8$ & $94.8 \pm 1.2$ & $4.90 \pm 0.26$ & $7.77 \pm 0.41$ & $12.2 \pm 0.3$ & $19.3 \pm 0.5$ \\
\hline H3 & Blackberry (Rubus caesius) & $20.9 \pm 0.3$ & $79.1 \pm 0.3$ & $256 \pm 24$ & $1224 \pm 113$ & $75.1 \pm 4.0$ & $359 \pm 19$ & $3.26 \pm 0.07$ & $15.6 \pm 0.3$ \\
\hline H4 & Plum (Prunus domestica) & $67.2 \pm 0.1$ & $32.8 \pm 0.1$ & $397 \pm 32$ & $590 \pm 48$ & $166 \pm 21$ & $248 \pm 31$ & $6.00 \pm 0.12$ & $8.92 \pm 0.18$ \\
\hline H5 & Apricot (Prunus armeniaca) & $29.4 \pm 0.2$ & $70.6 \pm 0.2$ & $68.7 \pm 3.0$ & $233 \pm 10$ & $10.4 \pm 0.6$ & $35.5 \pm 2.1$ & $3.46 \pm 0.08$ & $11.8 \pm 0.3$ \\
\hline H6 & Cherry (Cerasus vulgaris) & $44.6 \pm 1.1$ & $55.4 \pm 1.1$ & $179 \pm 16$ & $401 \pm 37$ & $58.3 \pm 6.0$ & $131 \pm 14$ & $6.51 \pm 0.07$ & $14.6 \pm 0.2$ \\
\hline H7 & Strawberry (Fragaria ananasa) & $31.7 \pm 0.1$ & $68.3 \pm 0.1$ & $211 \pm 15$ & $666 \pm 47$ & $46.1 \pm 2.6$ & $145 \pm 8$ & $2.74 \pm 0.05$ & $8.65 \pm 0.17$ \\
\hline H8 & Raspberry (Rubus ideaus) & $37.6 \pm 0.1$ & $62.4 \pm 0.1$ & $185 \pm 23$ & $492 \pm 62$ & $28.6 \pm 2.7$ & $76.2 \pm 7.2$ & $4.74 \pm 0.00$ & $12.6 \pm 0.0$ \\
\hline H9 & Orange (Citrus sinensis) & $46.3 \pm 0.2$ & $53.7 \pm 0.2$ & $60.2 \pm 5.1$ & $130 \pm 11$ & $4.12 \pm 0.04$ & $8.90 \pm 0.09$ & $1.86 \pm 0.02$ & $4.01 \pm 0.05$ \\
\hline H10 & Peach (Persica vulgaris) & $29.5 \pm 0.1$ & $70.5 \pm 0.1$ & $50.7 \pm 3.3$ & $172 \pm 11$ & $5.06 \pm 3.45$ & $17.2 \pm 11.7$ & $1.66 \pm 0.13$ & $5.62 \pm 0.44$ \\
\hline H11 & Plum (Prunus domestica) & $37.0 \pm 1.2$ & $63.0 \pm 1.2$ & $209 \pm 6$ & $564 \pm 15$ & $93.8 \pm 0.6$ & $254 \pm 2$ & $3.04 \pm 0.12$ & $8.21 \pm 0.32$ \\
\hline H12 & Plum (Prunus domestica) & $53.9 \pm 0.6$ & $46.1 \pm 0.6$ & $255 \pm 11$ & $473 \pm 19$ & $112 \pm 3$ & $208 \pm 6$ & $3.85 \pm 0.11$ & $7.15 \pm 0.20$ \\
\hline H13 & Plum (Prunus domestica) & $48.1 \pm 0.9$ & $51.9 \pm 0.9$ & $230 \pm 18$ & $478 \pm 37$ & $95.5 \pm 5.3$ & $198 \pm 11$ & $3.88 \pm 0.52$ & $8.06 \pm 1.08$ \\
\hline H14 & Plum (Prunus domestica) & $33.8 \pm 1.0$ & $66.2 \pm 1.0$ & $246 \pm 22$ & $727 \pm 64$ & $122 \pm 5$ & $360 \pm 15$ & $7.80 \pm 0.24$ & $23.1 \pm 0.7$ \\
\hline H15 & $\begin{array}{c}\text { Bullace (Prunus domestica } \\
\text { subsp. Syriaca) }\end{array}$ & $48.5 \pm 0.4$ & $51.5 \pm 0.4$ & $108 \pm 15$ & $222 \pm 31$ & $20.1 \pm 3.1$ & $41.5 \pm 6.4$ & $5.45 \pm 0.31$ & $11.2 \pm 0.7$ \\
\hline H16 & Cherry (Cerasus vulgaris) & $44.2 \pm 0.4$ & $55.8 \pm 0.4$ & $136 \pm 30$ & $308 \pm 67$ & $43.9 \pm 8.9$ & $99.3 \pm 20.1$ & $3.36 \pm 0.10$ & $7.59 \pm 0.23$ \\
\hline H17 & Strawberry (Fragaria ananasa) & $36.7 \pm 0.1$ & $63.3 \pm 0.1$ & $145 \pm 11$ & $396 \pm 31$ & $17.8 \pm 3.0$ & $48.6 \pm 8.1$ & $2.05 \pm 0.05$ & $5.57 \pm 0.13$ \\
\hline
\end{tabular}

Results of total phenolic (TP) content are shown in Table 2. The highest TP contents were determined in plum jams (B4 and H4). TP contents were under 100 mgGAE/100g in 6 samples (B9, B10, H1, H5, H9 and H10), between 100200mgGAE/100g in 10 samples (B3, B5, B6, B7, B8, H6, H8, H15, H16 and H17), between 200-300 mgGAE/100g in 8 samples (B1, B2, H3, H7, H11, H12, $\mathrm{H} 13$ and $\mathrm{H} 14)$.

Flavonoid contents are presented in Table 2. In case of two plum jams (B4 and H4) the flavonoid contents were higher than $150 \mathrm{mgCE} / 100 \mathrm{~g}$. B1, H12 and H14 samples showed flavonoid contents ranged between 100-149 mgCE/100g. Lower flavonoid contents (50-99 $\mathrm{mgCE} / 100 \mathrm{~g}$ ) were measured in 7 samples (B2, B5, B6, H3, H6, H11 and H13). In case of other samples (B3, B7, B8, B9, B10, H1, H5
$\mathrm{H} 7, \mathrm{H} 8, \mathrm{H} 9, \mathrm{H} 10, \mathrm{H} 15, \mathrm{H} 16$ and H17) the flavonoid contents were under 50 $\mathrm{mgCE} / 100 \mathrm{~g}$.

Total acid contents can be seen in Table 2. More than $10 \%$ total acid content was measured in H1 sample. In 5 jams (B8, H4, H6, H14 and H15) this content was between 5 and $10 \%$. The other samples showed lower total acid content.

Because of the different moisture content, TP content, flavonoid content and total acid content were also calculated in dry matter. All of the examined jams contained TP in important concentrations (Fig. 1.).

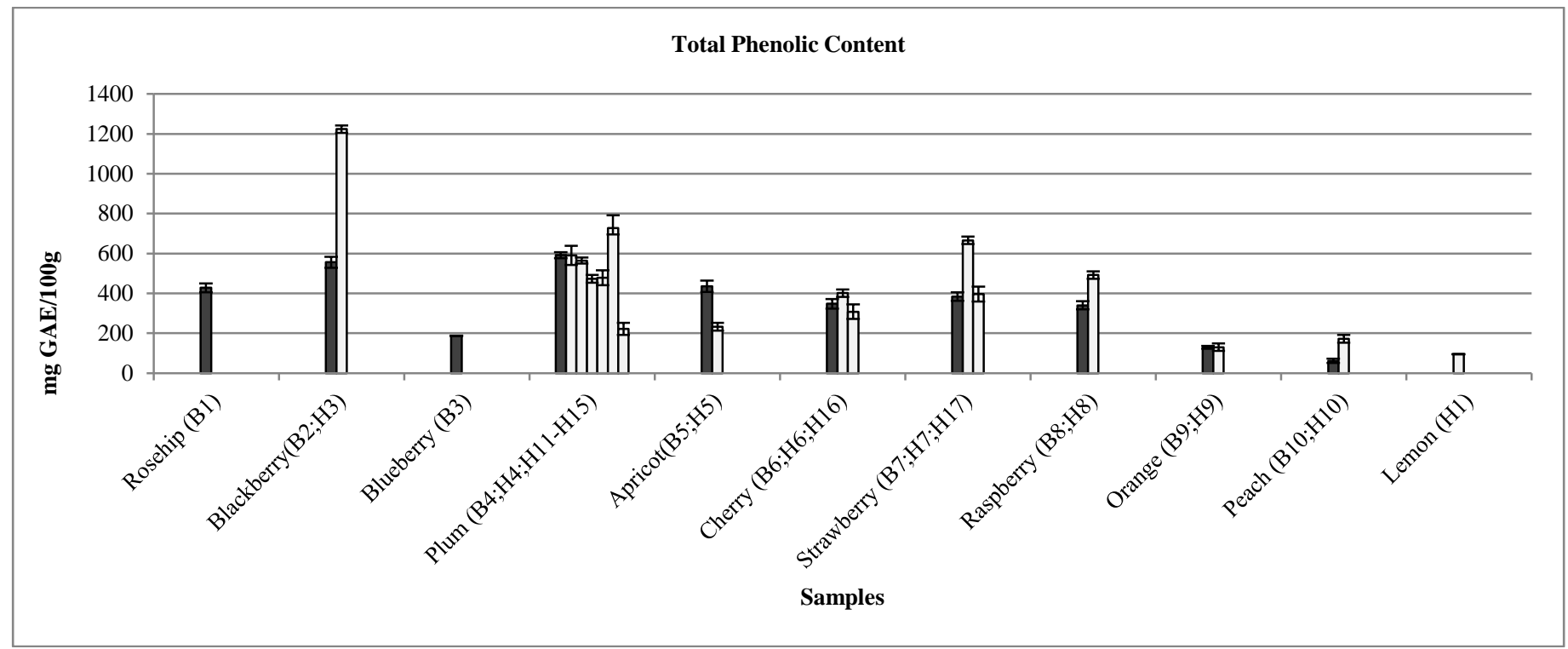

Figure 1 TP contents of examined samples (expressed in dry matter)

Higher than $1000 \mathrm{mgGAE} / 100 \mathrm{~g}$ TP content was measured in H3 sample which was a homemade blackberry jam. In case of $\mathrm{H} 1$ and B10 samples TP contents were lower than $100 \mathrm{mgGAE} / 100 \mathrm{~g}$. TP contents ranged between 100 and 800 mgGAE/100g in other jams. Among the commercial and the homemade jams, differences were determined. The most important differences were measured in case of commercial and homemade blackberry jams where TP content was two times higher in the homemade sample. Examining plum jams important differences were determined due to the different species of plums. For example, H15 sample was a bullace that contained much lower TP content than the others. In case of apricot jams the higher TP content was measured in the commercial jam that was almost two times higher than in the homemade jam. Important differences in case of cherry jams were not determined. The results of strawberry jams were diverse. In case of B7 and $\mathrm{H} 17$ samples there were no important differences, but $\mathrm{H} 7$ jam showed almost two times higher values than the other strawberry samples. Higher TP concentration was measured in the homemade raspberry jam (H8). Similar TP contents were measured in orange jams, however the homemade peach jam (H10) showed almost three times higher TP contents than the commercial peach jam (B10).

Examining the flavonoid contents, higher than $300 \mathrm{mgCE} / 100 \mathrm{~g}$ was measured in B4, H3 and H14 samples (Fig. 2), 


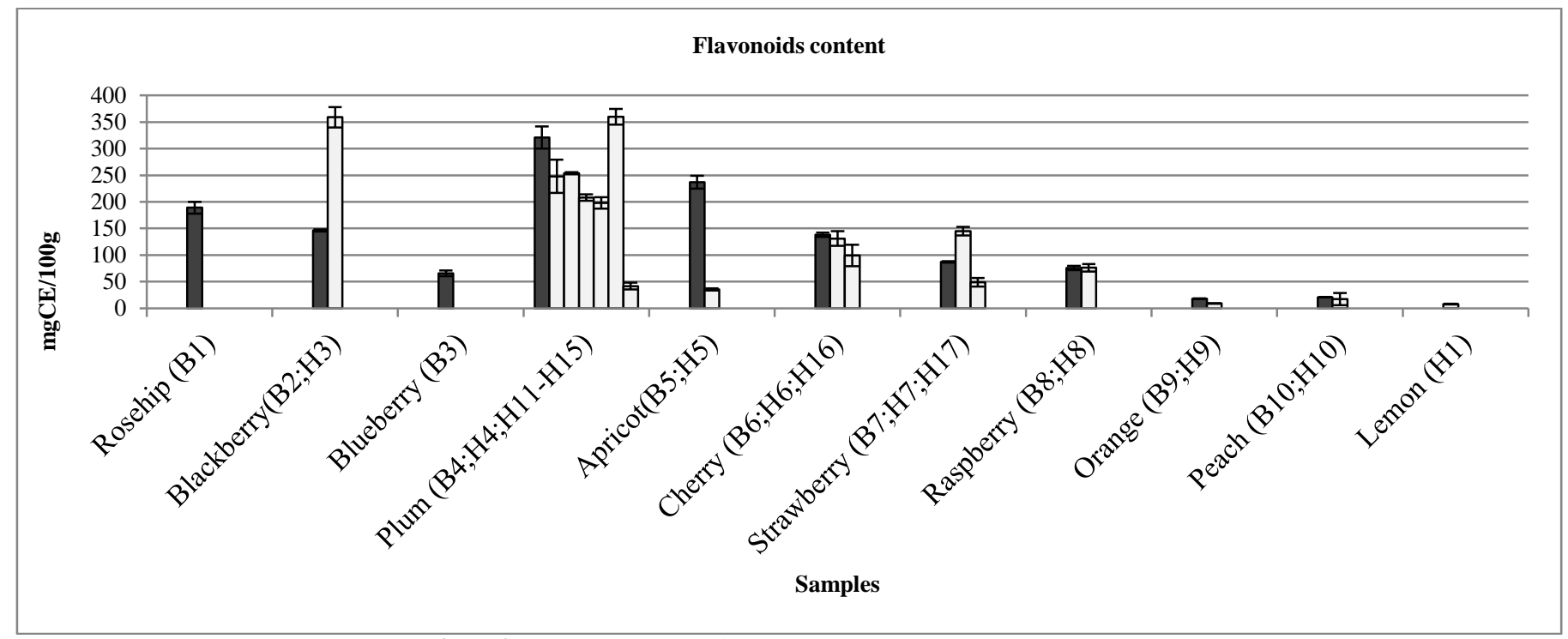

Figure 2 Flavonoid contents of examined samples (expressed in dry matter)

Flavonoid contents were between 200 and $299 \mathrm{mgCE} / 100 \mathrm{~g}$ in B5, H4, H11 and $\mathrm{H} 12$ samples. In case of 6 jams (B1, B2, B6, H6, H7 and H13) the concentration ranged between 100 and $199 \mathrm{mgCE} / 100 \mathrm{~g}$ and the other samples showed lower than $100 \mathrm{mgCE} / 100 \mathrm{~g}$. Flavonoid contents showed differences like TP contents. Homemade blackberry jam showed two times higher concentration than the commercial jam. In case of H14 and B4 samples flavonoid contents were similar, however the other plum jams showed lower concentrations. Much lower flavonoid content was determined in bullace jam. More than six times higher content was measured in commercial apricot jam than in the homemade jam. There were no important differences among cherry jams. A homemade strawberry jam (H7) had important flavonoid content compared to other strawberry jams. There were not any differences in case of raspberry and peach jam samples. The commercial orange jam showed two times higher concentration than the homemade orange jam.

Examining total acid content there was one sample that showed higher than $20 \%$ (H14) (Fig.3).

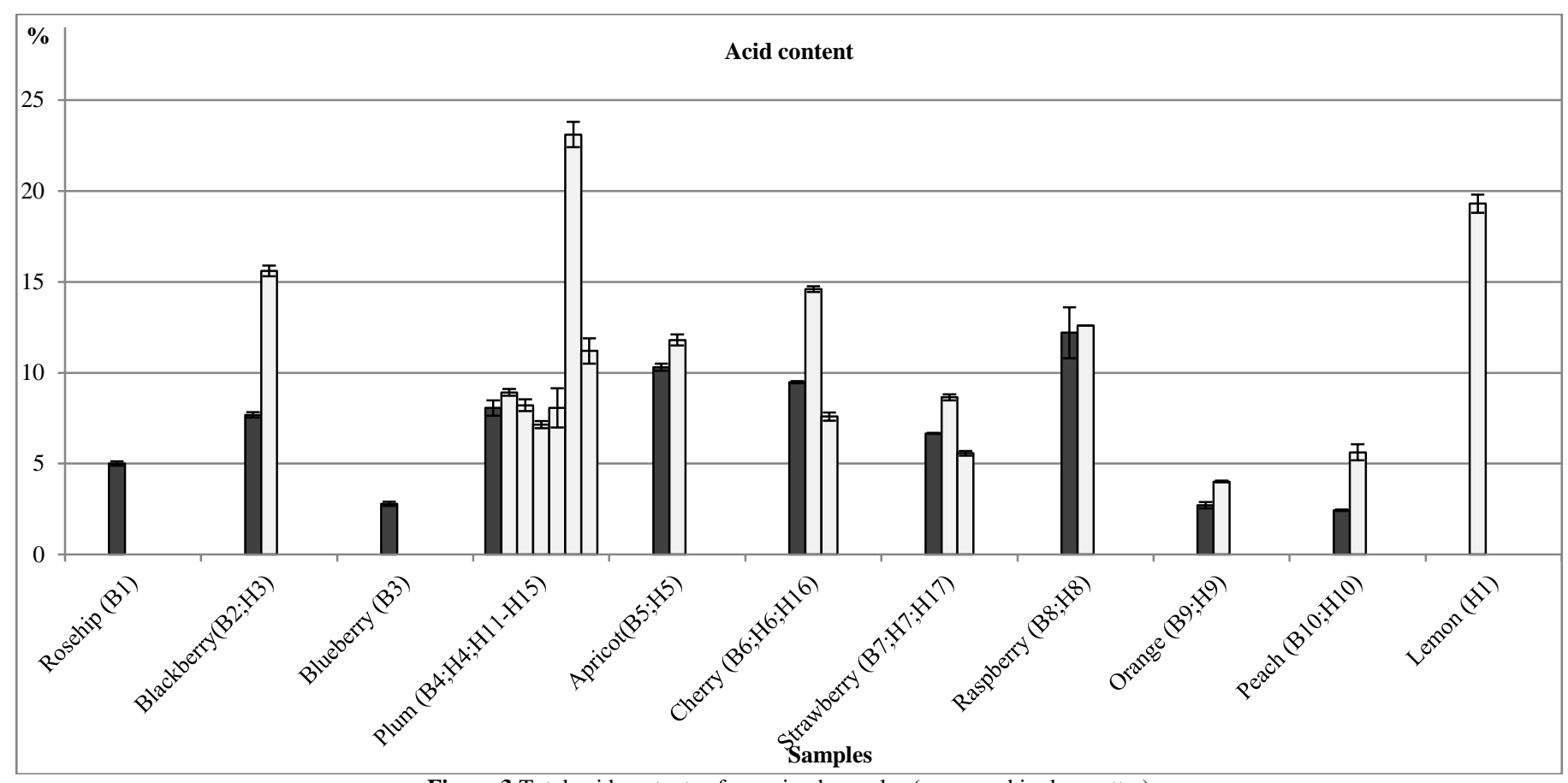

Figure 3 Total acid contents of examined samples (expressed in dry matter)

Outstanding total acid contents were measured in $\mathrm{H} 1$ and $\mathrm{H} 3$ samples. In case of other examined samples total acid contents were lower than $15 \%$. Homemade blackberry showed two times higher total acid content than the commercial product. Similar contents were determined in plum jams except for H15 and H14 because these samples showed different contents. In case of cherry jam samples, the highest content was determined in H6 sample. There were no important differences between strawberry and raspberry jams. Homemade orange and peach jams showed higher total acid contents than the commercial products.

Based on the results of LSD test, the examined jam types showed importan differences $(\mathrm{P}$ value $<0.05)$ in TP, flavonoid and acid contents. In case of TP content statistically verified differences were as follows: blackberry and plum jam $(\mathrm{P}$ value $=0.029)$, blackberry and apricot jam $(\mathrm{P}$ value $=0.004)$, blackberry and sour cherry jam $(\mathrm{P}$ value $=0.003)$, blackberry and strawberry jam $(\mathrm{P}$ value $=$ $0.015)$, blackberry and raspberry jam $(\mathrm{P}$ value $=0.010)$, blackberry and orange jam $(\mathrm{P}$ value $=0.000)$, blackberry and peach jam $(\mathrm{P}$ value $=0.000)$, plum and orange jam $(\mathrm{P}$ value $=0.005)$, plum and peach jam $(\mathrm{P}$ value $=0.004)$, strawberry and orange jam $(\mathrm{P}$ value $=0.030)$, strawberry and peach jam $(\mathrm{P}$ value $=0.026)$.

In case of flavonoid content statistically verified differences were as follows: blackberry and strawberry jam $(\mathrm{P}$ value $=0.026)$, blackberry and raspberry jam $(\mathrm{P}$ value $=0.024)$, blackberry and orange jam $(\mathrm{P}$ value $=0.004)$, blackberry and peach jam $(P$ value $=0.005)$, plum and apricot jam $(P$ value $=0.042)$, plum and sour cherry jam $(\mathrm{P}$ value $=0.013)$, plum and strawberry jam $(\mathrm{P}$ value $=0.004)$, plum and raspberry jam $(\mathrm{P}$ value $=0.005)$, plum and orange jam $(\mathrm{P}$ value $=$ $0.001)$, plum and peach jam $(\mathrm{P}$ value $=0.001)$.

In case of acid content there were no statistically verified differences among the examined jam types.

In summary, blackberry jams showed the most important differences from the other examined jams mainly in case of TP contents. Examining the flavonoid contents blackberry and plum jams showed significant differences from other jam types.

Analysing the jams according to their colours we determined that jams of red fruits showed much higher total phenolic content $(509 \pm 224 \mathrm{mgGAE} / 100 \mathrm{~g})$ than 
the jams of yellow fruits $(185 \pm 117 \mathrm{mgGAE} / 100 \mathrm{~g})$. Higher flavonoid contents were measured in red jams $(175 \pm 97 \mathrm{mgCE} / 100 \mathrm{~g})$ than in yellow jams $(48.3 \pm 77.2$ $\mathrm{mgCE} / 100 \mathrm{~g}$ ), however because of high standard deviations these results are not reliable. Very similar acid contents were determined in red $(9.55 \pm 4.67 \%)$ and in yellow $(8.42 \pm 5.81 \%)$ jams. According to the T-test homogenous variances were found in variance of red and yellow jams in TP contents, flavonoid contents and acid contents. Statistically verified differences ( $P$ values $<0.05)$ were determined between red and yellow jams in case of TP content (0.001) and flavonoid content (0.004). P value was 0.603 in case of acid content so red and yellow jams did not show any differences in acid content.

\section{CONCLUSION}

In this study 10 commercial and 16 homemade jams produced by using different fruits as raw materials were analysed. Homemade samples came from HajdúBihar County and commercial samples were brought from supermarkets. Dry matter and moisture contents, TP contents, flavonoid contents and total acid contents were measured. Samples showed different moisture contents and lower water contents were determined in commercial samples. Moisture content ranged between 50 and $60 \%$ in most of the products (10 samples). The lowest water content was determined in the commercial peach jam. TP contents, flavonoid contents, and total acid contents were very different comparing to different jams. These parameters could be influenced by moisture contents, fruit contents and preparing technologies. Additional influencing factors may be the collecting area of fruits, agricultural technologies and the weather. According to statistical analysis the examination of measured parameters can be able to differentiate of fruit jams.

Acknowledgement: The publication is supported by the EFOP-3.6.3-VEKOP16-2017-00008 project. The project is co-financed by the European Union and the European Social Fund.

\section{REFERENCES}

COUNCIL DIRECTIVE 2001/113/EC relating to fruit jams, jellies and marmalades and sweetened chestnut purée intended for human consumption (2002). Official Journal of the European Communities.

$\mathrm{Du}$ Toit, R., Volsteedt, Y., Apostolides, Z. (2001). Comparison of the antioxidant content of fruits, vegetables and teas measured as vitamin $\mathrm{C}$ equivalents. Toxicology 166, 63-69. https://doi.org/10.1016/S0300-483X(01)00446-2

Kanyó, T., Miklay, J., Taródi, M. (2015). Zöldség és gyümölcsfeldolgozás. Nemzeti Agrárszaktanácsadási, Képzési és Vidékfejlesztési Intézet, Budapest, 143.

Kim, D.O., Jeong, S, W., Lee, C.Y.(2003). Antioxidant capacity of phenolic phytochemicals from various cultivas of plums. Food Chemistry, 81, 321-326 https://doi.org/10.1016/S0308-8146(02)00423-5

$\mathrm{KSH}$ :

https://www.ksh.hu/docs/hun/xstadat/xstadat_eves/i_zhc023c.html?down=6434

Morelli, L.L.L., Prado, M.A. (2012). Extraction optimization for antioxidant phenolic compounds in red grape jam using ultrasound with a response surface $\begin{array}{llll}\text { methodology. Ultrasonics } & \text { Sonochemistry, } & 19, & 1144-1149\end{array}$ https://doi.org/10.1016/j.ultsonch.2012.03.009

Nowak, R., Olech, M., Pecio, L., Oleszek, W., Los, R., Malm, A., Rzymowska, J. (2014) Cytotoxic, antioxidant, antimicrobial properties and chemical composition of rose petals. Journal of the Science of Food and Agriculture, 94(3), 560-567. doi:10.1002/jsfa.6294

Olech, M., Nowak, R., Los, R., Rzymowska, J., Malm, A., Chrusciel, K. (2012).Biological activity and composition of teas and tinctures prepared from Rosa rugosa Thunb. Central European Journal of Biology, 7(1), 172 182. https://doi.org/10.2478/s11535-011-0105-X

Ryu, H.W., Song, H.H., Kim, K.O., Park, Y. J., Kim, D.Y.,Kim, J.H.,Oh, S. R (2016). Secondary metabolite profiling and modulation of antioxidants in wild and cultivated Euphorbia supina. Industrial Crops and Products, 89, 215-224. DOI: $10.1016 /$ j.indcrop.2016.05.011

Singleton, V.L., Orthofer, R., Lamuela-Raventos, M.(1999). Analysis of total phenols and other oxidation substrates and antioxidants by means of FolinCiocalteu reagent. Methods in Enzymology, 299, 152-178. https://doi.org/10.1016/S0076-6879(99)99017-1

Tiwari, P., Sangwan, R.S., Sangwan, N. S. (2016). Plant secondary metabolism linked glycosyltransferases: An update on expanding knowledge and scopes. $\begin{array}{lll}\text { Biotechnology Advances, } & 34(5), & 714-739\end{array}$ https://doi.org/10.1016/j.biotechadv.2016.03.006 